\title{
Spatially modeled high detail population and climate prospects for a European transect: an outlook to future patterns of vulnerability
}

\author{
C. Aubrecht, K. Steinnocher, M. Köstl, J. Züger \& W. Loibl \\ AIT Austrian Institute of Technology, Austria
}

\begin{abstract}
Population exposure mapping forms an important part and is usually considered the starting point for the assessment of the social dimension of vulnerability. Integration of social structure would then further differentiate situation-specific vulnerability patterns on a local scale. Census data available in inhomogeneous spatial reference units are still considered the standard information input for assessing potentially affected people, e.g. in case of an emergency. There is a strong demand on population data that are independent from administrative areas. Raster representations meet this demand but are not yet available for all European countries. In this paper we will present an approach of spatial disaggregation of population data for a European transect referring to current population statistics and anticipated future prospects. A recently published new data set providing the degree of soil sealing for the EU27+ countries is applied as basic proxy for population density in the spatial disaggregation model. In order to assess future patterns of climate change related vulnerability, results of a European regional climate model are considered for projecting the situation in the year 2030. Various variables such as 'heat wave frequency' and 'number of hot nights' will be accounted for in that regard featuring conditions regarded especially strenuous for elderly or physically weak persons. Integrated analysis of the population and climate prospects data enables identification of hot spots in the examined European transect, i.e. regions of high population density and particularly demanding projected climatic patterns. In the context of climate impact mitigation as well as for the assessment and management of future risks and emergencies, integrated and consistent spatial analyses on European scale are of utmost importance for decision making processes as well as for risk communication and future safety and security considerations.
\end{abstract}

Keywords: social vulnerability, population exposure, spatial disaggregation, climate prospects, regional climate model, heat wave. 


\section{Introduction}

Climate change and associated consequences are very likely to have substantial implications for human health. Climate change does not exist as a separate, single variable, but is rather characterized by a multitude of influencing parameters that are relevant for human well-being [1]. The assumption that many important environmental determinants of disease will be exacerbated is well supported by scientific evidence, but there has been a lack of research about the effects on human systems and how population and environmental factors interact to increase climate change induced vulnerability [2].

Based on evidence from epidemiological studies, Kovats and Akhtar [3] list a set of known health effects of weather and climate variability. Heat stress, for example, includes heat-related illness and death due to heat waves as well as associated deaths from cardio-respiratory disease. An increase in heat waves is considered one of the most certain impacts of climate change. Temperature extremes do generally affect all classes of population, but studies show that heat mortality risk varies with several social factors such as age in particular [4]. However, if heat exposure is severe enough, even healthy people are seriously susceptible to heat stroke.

For assessment of the social dimension of vulnerability, population exposure mapping forms an important part and is usually considered the starting point. Integration of social structure would then further differentiate situation-specific vulnerability patterns on a local scale. In this paper we will present an approach of spatial disaggregation of population data for a European transect referring to current population statistics and anticipated future prospects. In order to assess climate change related future patterns of vulnerability, results of a European regional climate model are considered for projecting the situation in the year 2030. Integrated analysis of the population and climate prospects data enables identification of hot spots in the examined European transect, i.e. regions of high population density and particularly demanding projected climatic patterns.

\section{Study area and input data}

The study was carried out for a North-South transect of Europe, covering Southern Sweden, Denmark, Germany, Poland, the Czech Republic, the Slovak Republic, Austria, Hungary, and Italy. Population counts on aggregated NUTS 3 level (dated 2006) were used as basic input data. Population prospects for 2030 including relevant structural information (e.g., elderly people) on a coarser spatial level of detail (NUTS 2) were obtained from the "EUROPOP2008 Convergence scenario, regional level" provided online by the statistical office of the European Union Eurostat [5].

As shown by Steinnocher et al. [6] spatial disaggregation of the available population distribution data are performed based on the recently published EEA Fast Track Service Precursor on Land Monitoring [7]. This is a newly available raster dataset for built-up areas featuring the degree of soil sealing for the EU27 and neighboring countries (a total of 38). 


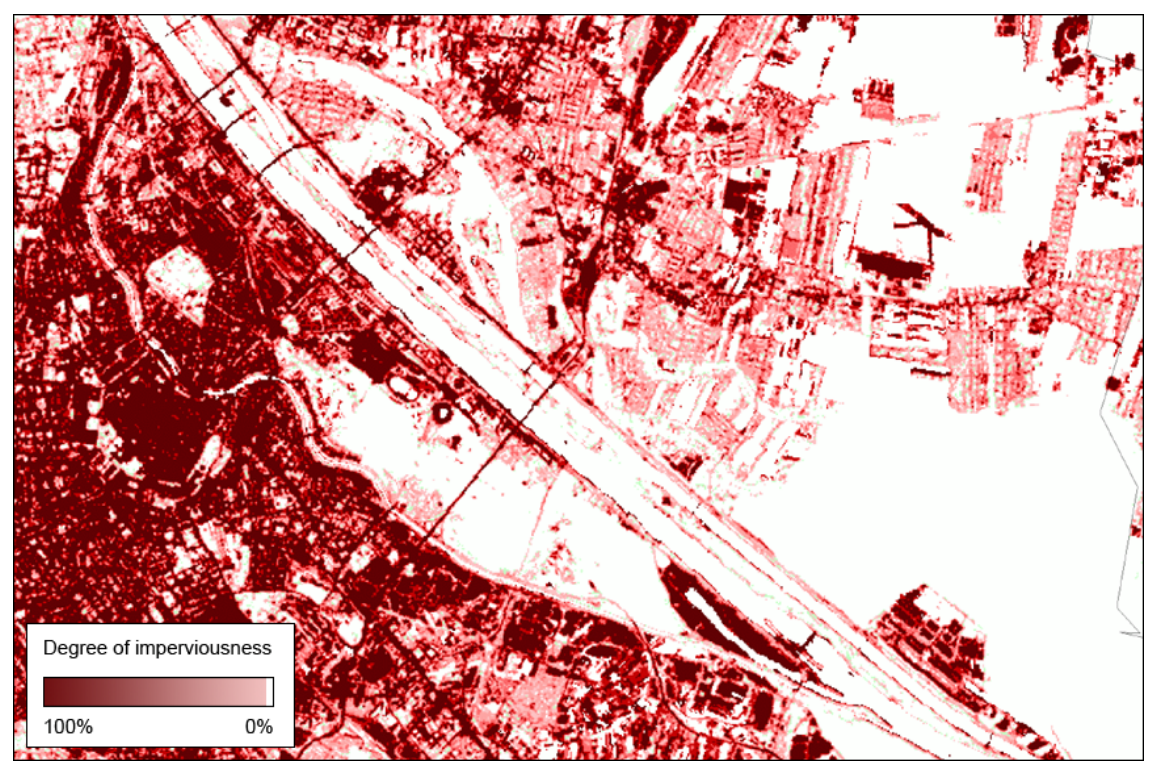

Figure 1: Sample of the EEA Fast Track Service Precursor on Land Monitoring core product ( $20 \mathrm{~m}$ resolution) which forms the basis for the aggregated $100 \mathrm{~m}$ layer used in this study showing the degree of soil sealing (imperviousness) for the city of Vienna, Austria.

It provides continuous degree of imperviousness ranging from $0-100 \%$ on a $100 \mathrm{~m}$ spatial resolution consistent on a European scale. An intermediate nonvalidated layer featuring a $20 \mathrm{~m}$ resolution exists as core data product for national and local-scale analyses (see figure 1). The data set is based on orthorectified high resolution satellite imagery (SPOT-4 and IRS LISS-3), acquired in two time windows selected by the countries for the years $2006+-1$. Supervised classification techniques were used for automatic mapping of builtup areas, followed by visual improvement of the classification results. The degree of soil sealing for the classified built-up regions was derived from calibrated NDVI (normalized difference vegetation index). According to the data description on EIONET (European Environment Information and Observation Network), the classification accuracy of built-up and non built-up areas (based on the $100 \mathrm{~m}$ grid) for the European product should be at least $85 \%$ [8].

Critical future environmental conditions intensified through climate change are modeled based on the consortial-simulations of the regional climate model COSMO-CLM performed by the Model and Data group (M\&D) of the MaxPlanck-Institute for Meteorology which operates as the data management division of the German Climate Computing Center (DKRZ). The CLM (Climate Local Model) evolved in the early 2000s as a climate-application of a newly developed high resolution non-hydrostatic local weather forecast model (less than $10 \mathrm{~km})$. Local-scale weather and climate models were eventually integrated 
into the unified limited area model for operational weather forecast and regional climate modeling COSMO4.

COSMO-CLM is the special setup of this model for climate simulations with the Consortium for Small-scale Modeling (consisting of two large groups of several European National Weather Services and the CLM-Community) currently working on further developments [9]. The CLM consortial-simulations are driven by the global climate model ECHAM5/MPI-OM1 (i.e., being a coupled atmosphere-ocean model [10]) and consist of two climate scenarios (A1B and B1, as defined by IPCC [11]) with two realizations each for the time period 1960-2100 [12]. Spatial resolution of the output geographical raster representations is approximately $18 \mathrm{~km}$.

\section{Methods}

\subsection{Modeling population distribution}

Census data available in inhomogeneous spatial reference units are considered the standard information input for assessing potentially affected people, e.g. in case of an emergency. However, there is a strong demand on population data that are independent from administrative areas. Raster representations meet this demand but are not yet available for all European countries. Re-allocating aggregated population counts from administrative areas to a regular grid requires spatial interpolation methods such as dasymetric mapping. This method applies ancillary data do disaggregate coarse population data to effective residential areas on a finer resolution. Land Use/Land Cover (LULC) maps are often used as a basis for the disaggregation process in that regard [13-15].

On a European scale CORINE land cover data (CLC) have been applied as basis for spatial disaggregation of population data, by 1) either estimating population density weights for the CLC classes [16] or 2) strictly considering mere residential CLC classes [17]. Both approaches are limited to the rather coarse spatial resolution of the CLC data set which leads to over- or underestimation of sparsely populated areas respectively. Applying the abovedescribed new high resolution soil sealing layer as a proxy for population (or rather housing) density the spatial interpolation can be improved significantly. Disaggregation for the reference year 2006 is performed for each NUTS 3 input region (basic reference unit), with an output grid featuring a defined spatial resolution of $1 \mathrm{~km}$. More detailed information on the applied disaggregation methodology, including preprocessing steps such as the elimination of nonresidential sealed surfaces for more accurate representation of distinct populated areas, is provided by Steinnocher et al. [6] who worked on an even finer output resolution of $500 \mathrm{~m}$.

Population prospects are taken into account for modeling future states of population distribution. Predicted changes in population counts available on NUTS 2 level from the "EUROPOP2008 - Convergence scenario, regional level" are disaggregated based on the assumption that the relative distribution patterns remain constant, i.e. reallocating population to those grid cells already populated 
in the 2006 reference year. Population densities for 2030 are thus again calculated based on the 2006 high resolution soil sealing layer for lack of available future prospects in that regard.

The EEA Fast Track Service Precursor on Land Monitoring has just recently been updated in the frame of the geoland2 project for the reference year 2009. This will allow extrapolations to the short to medium time scale in the near future. Structural population information inherent in the Eurostat population convergence scenario is used for additionally calculating the change of the proportion of elderly people (60+ years of age). These changes are again proportionally applied to the populated grid cells.

\subsection{Modeling future climate change related critical conditions}

In order to assess future patterns of climate change related vulnerability, results of the European regional climate model COSMO-CLM are consulted for projecting the situation in the year 2030. For the present study the IPCC scenario A1B is considered, projecting medium increase in $\mathrm{CO} 2$ concentrations for the time period 1960-2100. Various variables are calculated in that regard annually averaged over a 10-year reference period, such as 'hot night' and 'heat wave' counts. Hot nights are defined as nights with minimal temperatures not dropping below $20^{\circ} \mathrm{C}$ while heat waves are extended periods of several days featuring extremely hot summer weather. In a Central European context the heat wave definition after Kysely et al. [18, 19] proved to be most adequate, consisting of three requirements imposed on the period under consideration: 'Heat waves' are thus defined as 1) "consecutive periods of at least 3 days during which the daily maximum temperature $\left(T_{\max }\right)$ is higher than or equal to $30^{\circ} \mathrm{C}$ ", 2 ) "the mean $T_{\max }$ over the whole period is at least $30^{\circ} \mathrm{C}^{\circ}$ ", and 3) "the $T_{\max }$ must not drop below $25^{\circ} \mathrm{C}^{\prime}$. In the Eastern Alps such heat waves do not occur every year, but nonetheless have been observed several times in recent decades. Also in historical data series an increase in frequency and duration is noticed. Referring to episodes rather than single (hot) days allows for more robust statements regarding meteorological characteristics in future decades.

\subsection{Data integration and vulnerability classification approach}

Exposure to extreme weather (both hot and cold) has been associated with increased morbidity and mortality. Extreme meteorological conditions like heat waves and associated effects such as increased air pollution (in particular elevated concentrations of ozone and $\mathrm{PM}_{10}$, particulate matter of diameter less than $10 \mu \mathrm{m}$ ) are regarded especially strenuous for elderly and physically weak persons while additional gender-stratified analysis showed women to be more vulnerable [20-23]. Integrated analysis of the regional-scale population and climate prospects data enables identification of hot spots in the examined European transect, i.e. areas of high population density and particularly demanding projected climatic patterns as described and defined above. Results of the calculated climate variables are spatially overlaid on modeled future population distribution patterns and jointly analyzed also considering structural 
population information (i.e., elderly people). Differences to the present state are highlighted, thus enabling a first spatial assessment of future patterns of climate change induced vulnerability on European scale.

Table 1: Vulnerability classification matrix featuring 5 classes of vulnerability: zero (-), low (LV), medium (MV), high (HV), very high (VHV).

\begin{tabular}{|c|c|c|c|c|c|c|}
\hline \multirow{2}{*}{\multicolumn{2}{|c|}{$\begin{array}{l}\text { Vulnerability } \\
\text { Index }\end{array}$}} & \multicolumn{5}{|c|}{ Average annual number of heat waves } \\
\hline & & 0 & $<1$ & $1-<2$ & $2-3$ & $>3$ \\
\hline \multirow{5}{*}{  } & $1-<100$ & - & LV & LV & MV & $\mathrm{HV}$ \\
\hline & $100-<500$ & - & $\mathrm{LV}$ & MV & MV & HV \\
\hline & $500-<1000$ & - & $\mathrm{LV}$ & MV & HV & VHV \\
\hline & $1000-2000$ & - & MV & MV & $\mathrm{HV}$ & VHV \\
\hline & $>2000$ & - & MV & MV & VHV & VHV \\
\hline
\end{tabular}

In order to come up with a specific measure of vulnerability patterns, a vulnerability index is created and applied to the spatial domain. Table 1 shows the vulnerability classification approach using a correlation matrix of two selected variables, 1) the average annual number of heat waves, and 2) the absolute number of elderly people (60+ years of age) associated with the area under consideration.

Both input parameters are re-sampled to 5 categories which are then integrated to 4 distinct classes of vulnerability: low (LV), medium (MV), high (HV), and very high (VHV). In case an area does not feature any (predicted) heat waves the vulnerability index is set to 0 . The conceptually developed classification scheme is applied to both the present state and future conditions, thus enabling an illustration of trends driven by changing climatic characteristics.

\section{Results}

\subsection{Population distribution: present state and future prospects}

Resulting from the applied spatial disaggregation approach described above a refined output population raster is derived. Figure 2 shows the population distribution within the North-South European transect for the reference year 2006. On the left the input population counts on NUTS 3 level are shown, compared to the disaggregated $1 \mathrm{~km}$ raster product on the right.

Figure 3 shows the modeled future population distribution for the NorthSouth European transect, disaggregated based on the Eurostat population prospects for 2030 [5]. On the left the absolute density numbers for the year 2030 are illustrated, which at first glance do look pretty similar to the present state shown in figure 2. However, the right-hand part of the figure highlights the absolute population change over the period under investigation (2006-2030). It 



Figure 2: $\quad$ North-South European transect showing the population distribution for 2006 on 1) NUTS 3 level (left) and 2) on a $1 \mathrm{~km}$ resolution disaggregated population grid (right).

is clearly visible that large parts of Germany are likely to experience massive population decrease. The region of Bavaria is an exception from that rule, being more in line with the Southern European regions such as the Po-Region and generally large parts of Italy that feature strong increases.

Regarding the future distribution of elderly people, which are considered one part of the total population particularly vulnerable to extreme climatic conditions, predicted structural population developments were considered in the disaggregation process. Figure 4 illustrates the distribution patterns of an increasing number of aged people (60 or more years of age) in the future. The left part shows the current (2006) situation for a sample region in Eastern Austria, compared to the predicted future (2030) patterns on the right.

The spreading of population older than 60 years of age is particularly manifest in the highlighted three largest cities of Austria (Vienna, Graz, and Linz). According to the Eurostat scenario of 2030 [5] the relative share of elderly people in the total population will be increasing most vigorously in countries like the Slovak Republic and Poland, as well as in some parts of Germany. In the analyzed North-South European transect only one small region located in the Northern part of Germany (around the city of Hamburg) is likely to experience a relative decrease in the proportion of aged people. 



Figure 3: $\quad$ North-South European transect showing 1) the predicted population distribution for 2030 (left) and 2) the absolute population change from 2006-2030 (right), both on a $1 \mathrm{~km}$ resolution population grid.
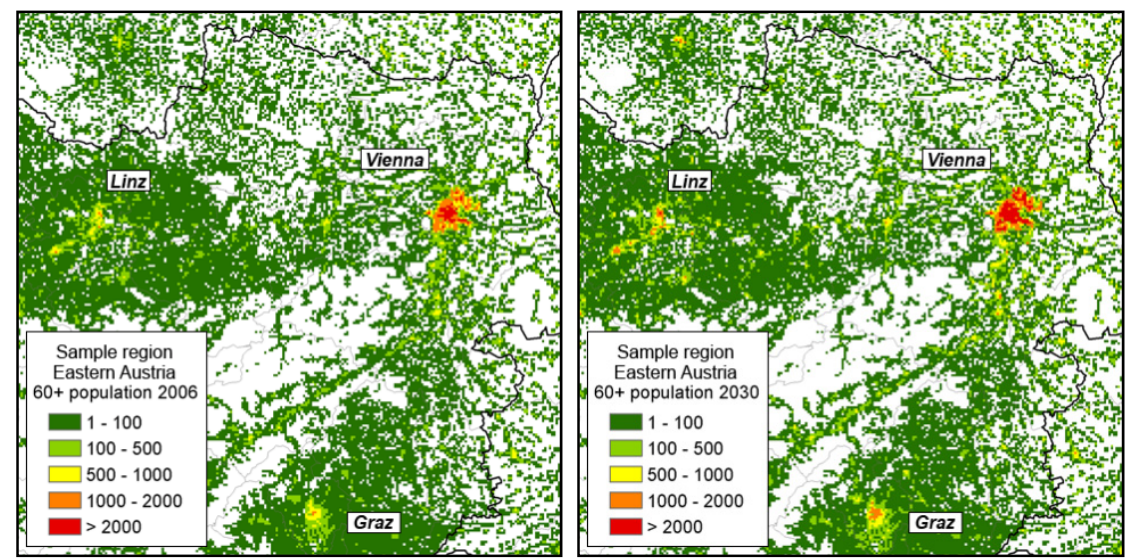

Figure 4: Sample region in Eastern Austria showing 1) the distribution of $60+$ population for 2006 (left) and 2) the distribution of 60+ population for 2030 (right), both on a $1 \mathrm{~km}$ resolution population grid. 



Figure 5: North-South European transect showing 1) the predicted average annual number of heat waves for the period 2030-2040 (left) and 2 ) the relative change in heat wave frequency comparing 20302040 to 2000-2010 (right), both calculated only for populated $1 \mathrm{~km}$ grid cells.

\subsection{Future patterns of vulnerability}

Several critical climatic variables were calculated using the climate prospects based on the COSMO-CLM regional climate model. The left part of figure 5 illustrates the future patterns of heat wave frequency in populated areas, averaged for a 10-year reference period spanning 2030-2040 to come up with a mean annual heat wave count number.

As expected, the Southern and Eastern parts of the North-South European transect including Italy, Hungary, the Slovak Republic, and Austria are likely to be most affected with more than three heat waves per year predicted for large parts of the populated regions. However, looking at the relative change in heat wave frequency (right part of figure 5), comparing the 2030-2040 prospect period to the present state (2000-2010), a rather strong increase is detected particularly in the Northern countries such as Denmark, Germany, and the Czech Republic, while for example Italy is likely to feature stable conditions or even a slight relative decrease in heat wave frequency in the future. 
Applying the newly developed vulnerability index classification scheme to the modeled results of population distribution and climate conditions enables a first consistent spatial assessment of future vulnerability patterns on European scale.

Figure 6 shows the climate change induced changing patterns of (heat-related) vulnerability considering elderly people the main focus due to their specifically high sensitivity to extreme meteorological conditions and associated effects. The left part of the figure illustrates the present state (2006) which is compared to the modeled future prospects (2030) on the right. It is evident that the areas of medium to high vulnerability are spreading towards the North. Regions of very high vulnerability are primarily found in major metropolitan areas, mostly driven by the increasing density of elderly population.
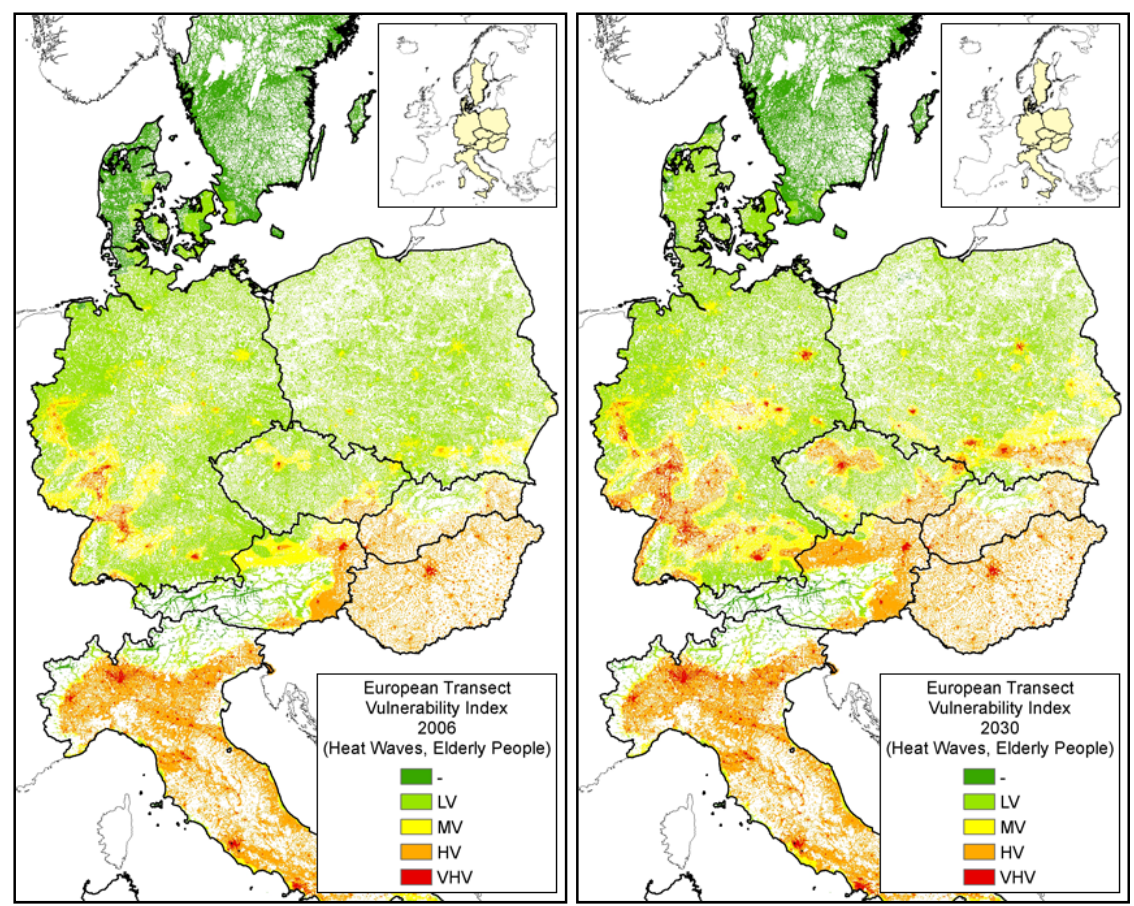

Figure 6: North-South European transect showing vulnerability index results for 1) the present state in 2006 (left) and 2) the predicted future state in 2030 (right), both on a $1 \mathrm{~km}$ resolution population grid.

\section{Conclusions and outlook}

Climate change entails an increase in problematic conditions for human health. It is thus considered a potential threat for all different kinds of population classes with elderly people highlighted as being particularly susceptible to extreme climatic conditions. Kovats and Lloyd [2] explain that in the near term, many of 
the mechanisms affecting human health are known, although magnitude of impacts and effectiveness of prevention are highly uncertain. Involving ecological shifts or emerging infections many changes are likely to occur that are not anticipated at present. Consideration of higher emission scenarios further increases uncertainty which involves unknown implications to social systems.

The concept of vulnerability has various dimensions applicable in the context of climate change research [24]. The presented approach of assessing and classifying vulnerability makes no claim to be complete. Particular selected parameters have been modeled and integrated in order to come up with prospects of future patterns. Nonetheless, in the context of climate impact mitigation as well as for the assessment and management of future risks and emergencies, consistent spatial analyses on European scale are of utmost importance for decision making processes as well as for risk communication and future safety and security considerations. The combination of changing demographic and climatic patterns introduces increased stress on local social networks that have long been critical to climate adaptation [25]. Climate change vulnerability hot spots are thus considered potential conflict areas. Community preparedness and strengthening coping capacity is essential for mitigating risks in that regard.

\section{Acknowledgements}

Part of the study was performed within the Core Information Service for Spatial Planning of the project geoland2 (http://www.gmes-geoland.info/) in the frame of the GMES (Global Monitoring for Environment and Security) initiative. The project geoland2 is a Collaborative Project (2008-2012) funded by the European Union under the $7^{\text {th }}$ Framework Programme (project number FP-7-218795).

\section{References}

[1] McMichael, A.J., Woodruff, R.E. \& Hales, S., Climate change and human health: present and future risks. The Lancet, 367(9513), pp. 859-869, 2006.

[2] Kovats, S. \& Lloyd, S., Population, Climate and Health. Population Dynamics and Climate Change, eds. J.M. Guzmán, G. Martine, G. McGranahan, D. Schensul \& C. Tacoli, New York, pp. 164-175, 2010.

[3] Kovats, S. \& Akhtar, R., Climate, climate change and human health in Asian cities. Environment and Urbanization, 20(1), pp. 165-175, 2008.

[4] Kovats, R.S. \& Hajat, S., Heat Stress and Public Health: A Critical Review. Annual Review of Public Health, 29(1), pp. 41-55, 2008.

[5] Eurostat, EUROPOP2008 - Convergence scenario, regional level, http://epp.eurostat.ec.europa.eu/cache/ITY_SDDS/de/proj_ro8c_esms.htm

[6] Steinnocher, K., Köstl, M. \& Weichselbaum, J., Grid-based population and land take trend indicators - New approaches introduced by the geoland 2 Core Information Service for Spatial Planning. New Techniques and Technologies for Statistics. NTTS 2011. Brussels, 9 pp., 2011. 
[7] EEA Fast Track Service Precursor on Land Monitoring - Degree of soil sealing 100m, http://www.eea.europa.eu/data-and-maps/data/eea-fast-trackservice-precursor-on-land-monitoring-degree-of-soil-sealing-100m-1

[8] LMCS High resolution soil sealing layer, http://sia.eionet.europa.eu /CLC2006/FTSP/built-up areas

[9] Rockel, B., Will, A. \& Hense, A., The Regional Climate Model COSMOCLM (CCLM). Meteorologische Zeitschrift, 17(4), pp. 347-348, 2008.

[10] Roeckner, E., Brokopf, R., Esch, M., Giorgetta, M., Hagemann, S., Kornblueh, L., Manzini, E., Schlese, U. \& Schulzweida, U., Sensitivity of Simulated Climate to Horizontal and Vertical Resolution in the ECHAM5 Atmosphere Model. Journal of Climate, 19(16), pp. 3771-3791, 2006.

[11] Nakicenovic, N. \& Swart, R., IPCC Special Report - Emissions Scenarios: Summary for Policymakers. IPCC: Geneva. 20 pp., 2000.

[12] Schubert, M., CLM Konsortial-simulations at the model and data group (M\&D). CLM Community-Assembly. Langen, 3 pp., 2007.

[13] Eicher, C.L. \& Brewer, C.A., Dasymetric Mapping and Areal Interpolation: Implementation and Evaluation. Cartography and Geographic Information Science, 28(2), pp. 125-138, 2001.

[14] Mennis, J. \& Hultgren, T., Intelligent Dasymetric Mapping and Its Application to Areal Interpolation. Cartography and Geographic Information Science, 33(3), pp. 179-194, 2006.

[15] Langford, M., Rapid facilitation of dasymetric-based population interpolation by means of raster pixel maps. Computers, Environment and Urban Systems, 31(1), pp. 19-32, 2007.

[16] Gallego, F.J., A population density grid of the European Union. Population and Environment, 31(6), pp. 460-473, 2010.

[17] Steinnocher, K., Weichselbaum, J. \& Köstl, M., Linking remote sensing and demographic analysis in urbanised areas. $1^{\text {st }}$ EARSeL Workshop of the SIG Urban Remote Sensing, ed. Hostert, Berlin, 8 pp., 2006.

[18] Kyselý, J., Kalvová, J. \& Kveton, V., Heat Waves in the South Moravian Region During the Period 1961-1995. Studia Geophysica et Geodaetica, 44(1), pp. 57-72, 2000.

[19] Kyselý, J., Mortality and displaced mortality during heat waves in the Czech Republic. International Journal of Biometeorology, 49(2), pp. 9197, 2004.

[20] Kysely, J. \& Huth, R., Heat-related mortality in the Czech Republic examined through synoptic and "traditional" approaches. Climate Research, 25(3), pp. 265-274, 2004.

[21] Gosling, S.N., Lowe, J.A., McGregor, G.R., Pelling, M., Malamud, B.D., Associations between elevated atmospheric temperature and human mortality: a critical review of the literature. Climatic Change, 92(3-4), pp. 299-341, 2008.

[22] Vaneckova, P., Hart, M.A., Beggs, P.J., Dear, R.J., Synoptic analysis of heat-related mortality in Sydney, Australia, 1993-2001. International Journal of Biometeorology, 52(6), pp. 439-451, 2008. 
[23] Sheridan, S.C. \& Kalkstein, A.J., Seasonal variability in heat-related mortality across the U.S. Natural Hazards, 55(2), pp. 291-305, 2010.

[24] Füssel, H.-M., Vulnerability: A generally applicable conceptual framework for climate change research. Global Environmental Change, 17(2), pp. 155-167, 2007.

[25] McLeman, R., Impacts of population change on vulnerability and the capacity to adapt to climate change and variability: a typology based on lessons from "a hard country". Population \& Environment, 31(5), pp. 286$316,2010$. 